\title{
An Energy Policy Analysis and Proposed Remedial Actions to Reduce Energy Crises in Pakistan
}

\author{
GHOUS BUX NAREJO*, FAWAD AZEEM**, AND SHEHNILA ZARDARI*** \\ RECEIVED ON 07.09.2016 ACCEPTED ON 22.11.2016
}

\begin{abstract}
Pakistan energy demand has grown exponentially over the last 2 decades. Reason behind increasing energy demand is excessive mobility of rural population to cities, rapid progression in industrial and transport sector, lack of policy making and implementation on the developed policies and improvements in living style. At present, Pakistan witness 5000-7000 MW power deficit in summer. To reduce the demand and supply gap, power plants across Pakistan are planned to be installed while some are under development phase. Power expansion plans cannot cope with the current energy shortfall since several years are required for them to get fully operational. Effective energy policy is the only key to address the existing shortfall. This paper discusses the initiatives that may be taken to reduce the power shortfall using energy efficiency and conservation, deployment of microgrids, utilization of renewable energy resources and effective research and development in energy sector. Since another most important issue evaluated in the research regarding the energy crises is energy efficiency and lack of compliance to government regulations for energy efficiency and conservation. Implementation on the policies developed for energy efficiencies and conservation has not been witnessed. Possible solutions on short term basis to lessen the energy crises have also been discussed in the paper.
\end{abstract}

Key Words: Microgrid, Rural Areas, Utility, Solar Photovoltaic, Policy.

\section{INTRODUCTION}

$\mathrm{P}$ akistan is among those countries where energy demand is increasing day by day. Increasing population and high migration rate towards cities increased the power demand of urban areas. According to 2012 stats total installed capacity for power generation is $21103 \mathrm{MW}$, where thermal share is $61 \%$ of total power generation with hydro energy putting its share up to $31 \%$ of total generation and nuclear energy contributes $4 \%$ to total power generation [1]. Power demand trends started increasing from 1970 till 1998 where total power increased from 9694-10554 MW i.e. increment of $860 \mathrm{MW}$ of power demand [1]. This was the distressing situation for Pakistan and for the policy makers to balance the demand and supply before it turns worst. From the year 2002-2007 supply growth rate started decreasing against the exponentially increasing demand that reached from 3.59\% growth rate in 2003 9.7\% in 2007-2008 [1]. This was the time where Pakistan started facing severe load shedding

\footnotetext{
* Department of Electronics Engineering, NED University of Engineering \& Technology, Karachi.

** Energy Research Center, COMSATS Institute of Information Technology, Lahore.

*** Department of Computer Science \& Software Engineering, NED University of Engineering \& Technology, Karachi.
}

Mehran University Research Journal of Engineering \& Technology, Volume 36, No. 2, April, 2017 [p-ISSN: 0254-7821, e-ISSN: 2413-7219] 
conditions across the country affecting the economics of the country. Fig. 1 shows demand and shortfall trends from 2009-2020 that is expected to touch $35738 \mathrm{MW}$ in 2020. To overcome the present energy crises a short term plan implementation is considerably needed to reduce economical destruction in the country. This paper discusses the short term plan based on 2-3 years projects to reduce shortfall in the country.

Demand side management based policies must be developed on national level to reduce the demand and supply gap. Power analysis Software tools, power conservation, maintenance and efficiency of the power systems are some key factors that can reduce demandsupply gap.

Zhou et. al. [2], developed a control scheme to answer the high demand response in peak hours, renewable energy hybrid system can be stored and released to grid when required at peak hours. To reduce the cost grid switching control technique has been adopted. Since power regulation control is somewhat expansive and increase the overall cost of the system. The adopted control system is purely based on renewable energy sources that can be installed at scattered places in urban areas. Sebastián, et. al. [3] have developed a systematic tool "HARE" that evaluate the measures needed to be taken at demand side in order to provide power quality up to the requirements

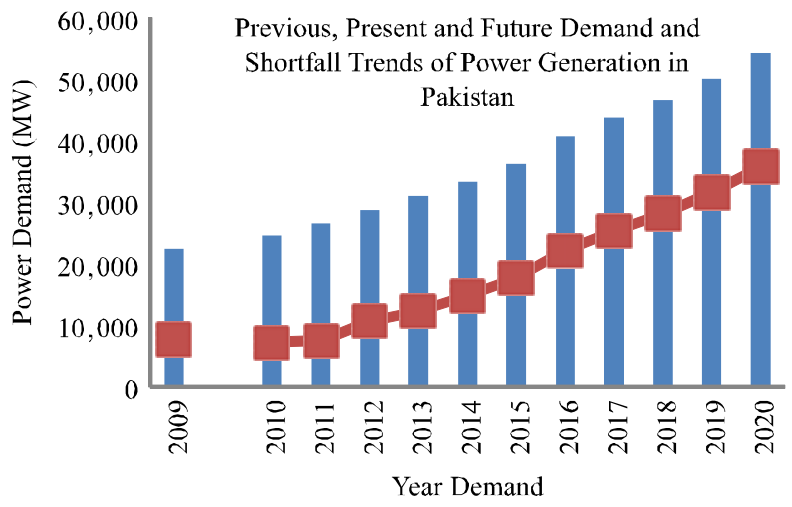

FIG. 1. PROJECTED REQUIRED DEMAND AND POWER SHORTFALL OF POWER GENERATION IN PAKISTAN [1] of end use level at the time of high demand situations. The tools have been specially designed for Hydro thermal power generating sources. Zhou, et. al. [4], designed a control strategy using solar photovoltaic and battery hybrid system that apply demand side management open loop control system to schedule a power flow of solar PV (Photovoltaic) battery hybrid system for 24 hours a day, another closed loop control scheme has been adopted to release power from the system when disturbance in the power system occurs. The aim of this demand side management is to minimize electricity cost. Demand side management related tools are essential for the stable power generation. Pakistan to meet the immediate demand, policies must be developed for short term demand fulfillment in the country.

As discussed in the literature review demand side management can be effectively fulfilled using renewable energy resources. Pakistan is abundant with renewable energy resources and hence these sources can be utilized to mitigate load shedding situation in the country. Demand side management of renewable energy resource using appropriate control strategies will be instrumental to achieve short-term demand fulfillment plan. Policies and plans in later sections are disused to reduce energy crises on short term basis.

\section{TECHNICAL AND FINANCIAL ISSUES AND POLICY BASED SOLUTION}

\subsection{Development of Microgrids}

Microgrid comprise of renewable energy based DG (Distributed Generation) having load near to generation sources. These sources include Solar, wind, mini hydro, micro turbines and fuel cells etc. Battery bank is one of the essential components for microgrid implementation. Pakistan is blessed with solar, Wind and micro hydel energy these generating sources can be utilized to reduce power 
shortfall in urban and rural areas. Demand side management is first and foremost requirement for introducing renewables to local grid, hence generation through volatile sources like wind and solar are intermittent in nature and cannot be relied upon once the load is unpredictable. In order to make the system flexible while utilizing renewable energy Dirk et. al. [5] has designed flexible demand side management system for city districts where renewable energy sources are operating. On the other hand solar energy available on every roof in the urban area can also form a microgrid distributed area wise in city. Thus formed microgrid will supply energy to the national grid via reverse metering concept using power electronic converters. A typical microgrid structure is shown in Fig. 2. DG that is generation of Electrical Power near load at Distribution System is a new technique. Distribution system consist of Renewable energy source for power generation these renewable energy sources includes solar energy, wind energy etc. [6]. Renewable Energy sources, with storage such as super capacitors and battery banks forms microgrid [8]. Microgrid can work in two modes that include interconnected mode and Islanded mode. In grid connected mode microgrid is connected with the public grid and in islanded mode microgrid works autonomously providing electrical power to local load. Since renewable energy sources are intermittent in nature, due to this fact Microgrid needs control strategy for its reliable operation while maintaining power quality. Electronic interfaced inverters are the major components of Microgrid in Islanded or grid connected mode [10]. These inverters are responsible for the control of active and reactive power to maintain reliable power sharing between renewable energy generators [10].

\subsection{Power Conservation}

Energy conservation is also one of the significant factors that are to be addressed. Local load in urban and rural areas must conserve energy in order to respond to power demands. It has been observed several times in big cities that street lights continue to glow all day long, on the other hand gas geysers runs 12 months a year which severely reduces natural reserves of country. Residents also do not take care of unnecessary loads that continue to consume energy for hours. Followings points are contributory for achieving energy conservation.

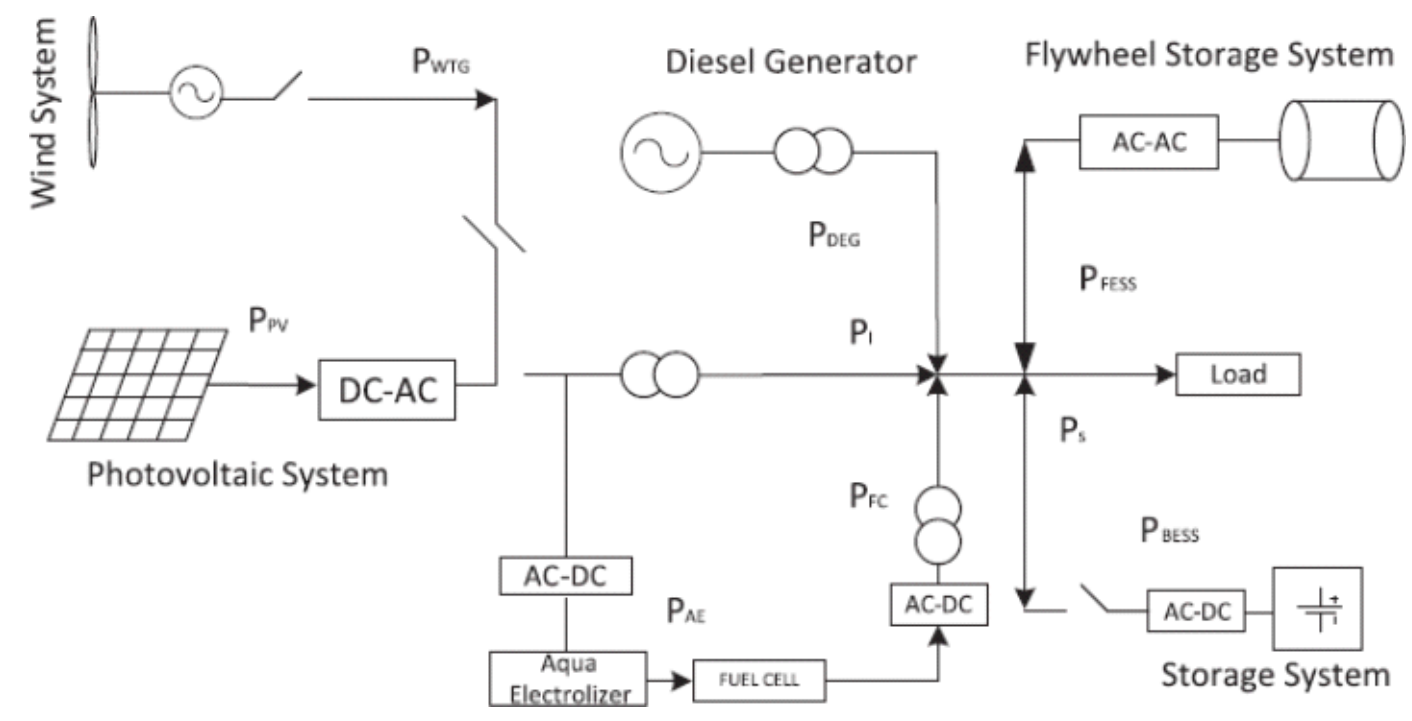

FIG. 2. STRUCTURE OF MICROGRID [6] 
- Utilization of state of the art and efficient utility products like LEDs (Light Emitting Diode), efficient fans, split air conditioners etc.

- Specific time for utilizing heavy loads like iron, motor pumps etc. These loads must operate in off-peak hours.

- Utilization of solar geysers instead of using traditional one.

- $\quad$ Restriction from the utility company must be applied as no more than 3 same utility products handled per home like air conditioners, refrigerators, televisions etc.

- $\quad$ Commercial areas like shops may not utilize additional lights in shopping malls, corridors etc.

- $\quad$ Office hours should follow sunlight working hours and get closed as soon as it turns dark to save additional electricity.

- $\quad$ There should be no extra lighting outside residential areas.

\subsection{Financial Loans for Renewable Energy}

Financial loans to commercial and residents must be provided in order to electrify homes and offices using renewable energy. The policy to return loan must be client friendly that is payment on monthly bases (installments) there should be ways to pay the installments. One proposed way to pay the loan should be generating excess energy and supplying to load. Utility company accumulates the total units provided by any consumer to grid and accordingly utility company pay money to bank instead of paying it back to customer. This way will provide peace of mind to the end consumer and people will be more willing to install and generate excess energy. This will reduce overall burden on the utility grid. This option can be availed using concept of reverse metering; tariff must be settled by NEPRA (National Electric Power Regulatory Authority) for per unit energy pay back.

\subsection{Electricity Theft Reduction}

Electricity theft is the one of the first-born dilemma faced by utility companies in the country. Since electricity theft is one of the major causes of shortfall. Survival of utility companies is in finances that are recovered from the consumers once electricity is utilized. Without paying bills hurts the overall system in terms of efficiency and reliability which results in power shortfall. To reduce power shortfall electricity theft must be clogged for better performance of the company.

\subsection{Bills Recovery}

As mentioned bills recovery is mandatory for survival of the electricity system. There should be a complete policy for bills recovery mechanism. One proposed mechanism in this paper is EBRC (Electricity Bills Recovery Committee) working of this committee would be to distribute team member area wise in metropolitan area. The teams in their respective area will be responsible for bill recovery within the first 10 days of the month. Those no paying bills may be intimated using cell phones SMS (Short Message Service), emails and in the end face to face by EBRC team members. On no payments electricity may be cut off for the complete month. The sole purpose of EBRC will be bill recovery. Team members may be changed area wise hence one team will not work in particular area on permanent basis but will be changed area wise randomly every month. This will further make the process transparent.

\subsection{Energy Conservation Based Lectures in Rural and Urban Areas}

Still in several areas of Pakistan especially in rural areas people utilizes electric bulb for their needs. efficient electric water pumps are being utilized in homes in urban areas, tube lights and bulbs are still utilized in washrooms, offices utilize complete 8 hours air conditioner weather it is needed or not. Energy conservation based lectures must be given in schools, offices, universities to reduce load while conserving energy. Each and every person in rural and urban area must understand the energy situation so he or 
she may contribute to get rid of power shortfall conditions. This can be only done while giving brief lectures on power conservation in Universities, Offices, schools and on televisions. Other possible options includes SMS for energy conservations, giving lectures in mosques for energy conservation etc.

\subsection{Utilization of Better and Efficient Transmission Line and Components}

Key steps for improving transmission grid flexibility and efficiency include:

- $\quad$ Taking out of service, key transmission lines not currently in operation to improve voltage violations [7]. This will also reduce corona losses [8].

- $\quad$ RASs (Remedial Action Schemes) or SIPSs (System Integrity Protection Schemes) should be used to improve the reliability of the grid and improve the operational efficiency.

- $\quad$ Proper load management reduces the requirement to increase transformer, cable sizes and generator capacity.

- Sufficient reactive compensation to improve system efficiency.

- Better quality equipment to be used in rural areas and urban areas [7].

- Installation of upgraded SCADA (Supervisory Control and Data Acquisition) software to optimize transmission and monitor its losses [9]

- Reconductoring a transmission line especially where transfer capacities are restricted by their thermal ratings, reconductoring can be a viable solution to reduce line losses and improve thermal performance.

- Using Superconductor where possible to reduce line losses.
- Use of Power flow control which is an electrical device or system that can supply fast-acting active or reactive power on transmission lines [8].

A component in transmission system introduces its own inefficiency to the entire system. One individual component with a poor efficiency rating has a multiplicative effect on the rest of the system, therefore, critical components should have the highest efficiency.

Using corrective maintenance instead of preventive maintenance for critical equipment including conductors, insulators and transformers also improves overall system efficiency and reduces down time as well.

\subsection{Geographical and Climatic Suitability of Power Plant Installation}

Pakistan in blessed with renewables (soar, wind, hydro), Natural gas, and coal reserves. Having versatile potential of power generation, Pakistan is among the states where several power generation sources (Renewable and Conventional) can be installed to harness electrical power. These power generation sources can be installed according to the classification of geographical and climatic suitability of generating source. The classification according to climatic and geographical suitability will reduce the generation cost which in turn will be an efficient and cost effective way power generation. Thar areas where abundant coal reserves are available can be utilized to install coal fired plant. The cost of coal transportation will be reduced on the other hand several areas like Jhampir and Badin of Sindh are abundant with wind energy, a microgrid utilizing wind can be installed rather using conventional energy that includes high lossy transmission system. In southern and upper Punjab solar energy is abundant these areas can utilize solar energy to generate power. In upper northern areas a microgrid can be implemented using microhyedel plant and water streams as a clean and reliable source of power generation. This 
diversified power generation classification can reduce overall cost because of indigenous fuels availability in those particular areas. A policy to classify power generation sources according to geographical and climatic suitability may reduce the operating and generating cost.

\section{CONCLUSION}

Demand side management with integration of renewable energy based microgridsis the key factor to reduce energy shortfall. Economy of Pakistan is governed by industrial and agricultural sectors and both of these sectors require reliability and energy surety. To increase GDP (Gross Domestic Product) rate and to strengthen the economy immediate actions are required to fulfill energy demand of the country. All plans and policies discussed in the paper can be implemented immediately with low cost solutions. Average time to complete these short term plans would be in between 3-4 years. Furthermore, mid-term and long term plans must also be developed for strengthening the energy sector and power reliability on permanent basis, however, short term polices can be extended to transform long-term plans in the country. As shows an uncontrolled energy shortfall will severely effects the power sector of Pakistan. If measures on long term plan like installation of state of the art power plants and transmission and distribution systems not installed then it will be a problematic situation to cope with the exponentially rising power demands. To overcome the discussed scenario planning and policies are needed to be developed right at the moment for immediate and long term solution for energy sector of Pakistan.

\section{ACKNOWLEDGEMENTS}

This research has been supported by seminars and lectures organized by Energy Research Center, COMSATS Institute of Information Technology, Lahore, Pakistan. Authors special thanks to all the Speakers of Seminars on Energy Conversion, Hydel Energy, and Solar PV Energy, for their contribution and sharing their thoughts for policy making of energy in Pakistan.

\section{REFERENCES}

[1] Rauf, O., Wang, S., Yuan, P., and Tan, J., "An Overview of Energy Status and Development in Pakistan", Renewable and Sustainable Energy Reviews, Volume 48, pp. 892-931, 2015.

[2] Wu, Z., and Xia, X., "Optimal Switching Renewable Energy System for Demand Side Management", Solar Energy, Volume 114, pp. 278-288, 2015.

[3] Püschel-Løvengreen, S., Palma-Behnke, R., and van Campen, B., "Systematic Tool to Plan and Evaluate Demand Side Strategies during Sustained Energy Crises in Hydrothermal Power Systems", Electrical Power and Energy Systems, Volume 71, pp. 305-314, 2015.

[4] Wu, Z., Tazvinga, H., and Xia, X., "Demand Side Management of Photovoltaic-Battery Hybrid System", Applied Energy, Volume 148, pp. 294-304, 2015.

[5] Müller, D., Monti , A., Stinner, S., Schlosser, T., Schütz, T, Matthes, P., Wolisz, H., Molitor, C., Harb , H., and Streblow, R., "Demand Side Management for City Districts", Building and Environment, Volume 91, pp. 283-293, 2015.

[6] Mahmouda, M.S., Hussain, S.A., and Abido, M.A., "Modeling and Control of Microgrid: An Overview", Journal of the Franklin Institute, Voulume 353, pp. 2822-2859, 2014.

[7] Kory, W.H., Shmuel, S.O., and O’Neill, R.P., “A Review of Transmission Switching and Network Topology Optimization", IEEE Conference on Power and Energy Society General Meeting, pp. 1-7, [ISSN: 1944-9925], 2011.

[8] Jackson, R., Omer, C.O., Kirkham, H., Fisher, E., Burkes, K., Starke, M., Mohammed, O., and Weeks, G., "Opportunities for Energy Efficiency Improvements in the US Electricity Transmission and Distribution System", Oak Ridge National Laboratory Oak Ridge for the US Department of Energy, pp. 3-9.

[9] "National Power Policy 2013", Ministry of Water \& Power", pp. 15, Government of Pakistan.

[10] Nikos Hatziargyriou, Microgrid Architecture and Control, IEEE Press, 2014. 